\title{
Rational Medicine Prescription and Adherence to Prescription Format: A Description of Practices in the Private Sector in Addis Ababa, Ethiopia
}

Getahun Asmamaw Mekuria ( $\sim$ getahunasmamaw12@gmail.com )

Arba Minch University

Nahu Ejigu

Arabisa Health Center

Dinksew Tewihubo

Medda Wolabu University

Wondim Ayenew

University of Gondar

\section{Research Article}

Keywords: Essential medicines list, Ethiopia, Prescribing Pattern, Rational drug use, WHO core drug use indicators, private health sector

Posted Date: August 27th, 2021

DOI: https://doi.org/10.21203/rs.3.rs-842102/v1

License: @ (i) This work is licensed under a Creative Commons Attribution 4.0 International License. Read Full License 


\section{Abstract}

Background: In Ethiopia, despite the private health sector's role in healthcare delivery is growing, studies on private health sector prescribing practices are uncommon. The main aim of this study was to evaluate the private health sector's rational prescribing practices and adherence to prescription format, using some of the World Health Organization (WHO) core drug use indicators in Addis Ababa, Ethiopia.

Method: A retrospective cross sectional study design was used to collect quantitative data from prescriptions prescribed and dispensed by private health sectors in the Lemi-kura sub-city, Addis Ababa. The study was conducted from June to July, 2021. The WHO criteria were used to evaluate prescribing and prescription completeness indicators. Prescriptions, kept for the last 1-year that prescribed between January 1, 2020 to January 1,2021 by private drug outlets, were analyzed. A combination of simple random sampling and systematic sampling procedures were employed. All the statistical calculations were performed using SPSS $®$ V 20.0 software.

Result: Off total of 1,200 prescriptions, 2,192 drugs were prescribed and the average number of drugs per prescription was 1.83 (Standard Deviation (SD) $=0.9$ ). Generic names, antibiotics, injections, and issued from national essential medicines list accounted for $77.4 \%, 63.8 \%, 11.5 \%$, and $80.6 \%$ of all prescriptions, respectively. The patients' full names, ages, and sexes were mentioned in $99 \%, 95.3 \%$, and $96.3 \%$ of prescriptions, respectively. The patient's card number $(54.3 \%)$ and weight (2.3\%) were not adhered to properly. The drug name, strength, dose, frequency, duration, and how to use, ranges from 85 to $99 \%$ of the prescriptions. Dosage forms (35.5\%) and diagnoses (31.7\%) were less likely to be completed. Only $36.6 \%$ and $25.8 \%$ of prescriptions, respectively, contained names and qualifications of prescribers. Obtaining prescription papers with the full name (9\%), qualification (1.3\%), and signature (26.8\%) of the dispenser, and date of dispensing $(0.7 \%)$, is extremely difficult. Interestingly, no dispenser filled out all of this information on a single prescription.

Conclusion: The study's findings indicated rational prescribing and prescription completeness indicators were all considerably deviate from WHO standards and hence unsuitable. To promote rational medication use, health practitioners in the private sector should be given regulatory interventions, ongoing monitoring from relevant bodies, and regular training on good prescribing and dispensing practices.

\section{Introduction}

Medicines play a crucial role in the delivery of quality healthcare services. The appropriate use of medications is critical to the improvement of a patient's disease condition. ${ }^{1}$ The improper use of medicine, on the other hand, may have unintended consequences for the patient. For example, side effects, unwelcome costs, sickness mistreatment, and antibiotic resistance. ${ }^{2,3}$ WHO defines rational medicine use as patients' use of medications for the specified clinical ailment, in the proper dose, in the appropriate dosage forms, for an adequate amount of time at minimal cost. ${ }^{4} \mathrm{~A}$ prescription is frequently used to communicate between the prescriber and the dispenser. Irrational drug usage is still a problem around the world. Thus, more than half of all drugs are prescribed and distributed in an unintended manner, according to WHO estimates. ${ }^{5}$ Because of this, incorrect drug use can lead to misuse, and overuse or underuse of medications can lead to a shortage of finite resources and associated health risks for individuals and communities. ${ }^{6}$ Furthermore, prescribing practices and prescriber behaviors have a vital influence in determining the public's health future in any country or region ${ }^{7}$. As a result, the WHO prescribing indicators are used as a standard since they may be used to define what intervention should be used to rectify a prescription problem when all of them are considered. If any of these fundamental signs fails to meet the standard, it might contribute in poor health outcome. ${ }^{5}$

In Ethiopia, irrational prescribing and poor compliance with prescription format practices are reported. ${ }^{8-11}$ However, evidence suggests that similar outcomes are uncommon in the country's private health sector prescribing practice. Despite the fact that the private health sector's involvement in healthcare delivery is expanding. ${ }^{10}$ As a reason, a high number of prescriptions are projected to come from the private sector. ${ }^{12}$ Irrational prescription is common in the private sector; for example, only a small percentage of drugs are prescribed by their nonproprietary names, and inaccuracy is designated as a violation of WHO's key indicators globally. ${ }^{1}$

Therefore, a periodic examination of medicine prescribing practices in a private health facility will aid in identifying specific medication use issues, educating practitioners on rational medicine prescription, and providing policymakers with important data for revising medicine-related policies. This study aimed to evaluate the private health sector's prescribing practices and adherence to fundamental prescription information, using some of the WHO core drug use indicators in Addis Ababa, Ethiopia. The findings of this study will aid in prioritizing the most important intervention areas for rational medicine use. It will also help as a starting point for researchers who want to do more research into the factors that influence drug usage patterns in private sectors.

\section{Material And Methods Study area and period}

Addis Ababa, the capital of Ethiopia has eleven administrative zones. In the city, nearly $94 \%$ of healthcare facilities are private. ${ }^{10}$ The city has more than 25 and 759 private for profit hospitals and clinics, respectively. Similarly, more than 308 pharmacies, 249 drug stores, and 1 rural drug vendor are hosted in the city. ${ }^{13}$ The sub-city of Lemi-kura is east of the Addis Ababa municipal administration. It is a newly reorganized administrative zone composed of ten woredas, which has been active since $2020 .^{14}$ The research was carried out at eight private community pharmacies and drug stores in the Lemi-kura sub-city. The study was carried out from June to July, 2021.

\section{Study design}

A retrospective cross sectional study design was used to collect quantitative data from prescriptions prescribed from private health institutions was carried out in randomly selected private community pharmacies and drug stores placed at the Lemi kura sub-city. The WHO criteria were used to evaluate both types 
of indicators (prescribing and prescription completeness indicators). ${ }^{5}$

\section{Sampling}

A combination of simple random sampling and systematic sampling procedure was employed in this investigation. ${ }^{15}$ The study site (Lemi-cura sub-city administration) was chosen first by lottery, then eight woredas in the sub-city. Then, one pharmacy and one drug store from each of the sub-woredas. For each category, the outlets are chosen in order, starting with a randomly selected outlet and progressing in a 10-outlet interval. As a result of the probability, a total eight, four pharmacies (named Gammel, 16, Werramo and Dudu) and four drug stores (named Yodahe, Anbessa, Hasset, and Belay) were chosen. Following that, private healthcare prescriptions were filtered out by excluding prescriptions from public health facilities, that were illegible or unclear, with only non-drug products (such as medical supplies, fluids, nutritional products), and issued before or after the specified prescription time. Prescriptions were chosen from those prescribed between January 1, 2020, to January 1, 2021. A systematic random sampling technique was then utilized to choose prescriptions obtained from private health facilities by taking every five prescriptions at drug outlets. The sampling interval was obtained by dividing 6,000 (total number of prescriptions fulfilled the criteria) by 1,200 (desired sample size). The sample size was determined based on the WHO guidelines, at least 600 encounters should be included in the sample. ${ }^{16}$ As a result, prescribing indicators were evaluated retrospectively using 1,200 prescriptions from eight different pharmacies and drug stores (150 prescriptions from each).

\section{Data collection}

In this study, WHO-designed data collecting forms based on criteria were used. The data on prescribing and completeness indicators were collected by three well-trained pharmacists by observing prescriptions. Data from prescription paper was filled out on a well-structured questionnaire by the collectors.

\section{Data analysis and interpretation}

The data was entered and analyzed using SPSS V 20.0 statistical software. In the statistical analysis, the indicators were reported as frequencies, averages/means, percentages and proportions. The findings were interpreted using WHO completeness and prescribing indicator standards.

\section{Completeness and prescribing indicators}

The WHO criteria for completeness and prescribing indicators were used in this study. As a result, common factors such as the prescriber's identity and drugrelated information were used to assess the prescription completeness. As a result, the adherence percentage of patient information (age and gender, wight, and card number), treatment information (drug name, drug strength, dose, frequency, duration, dosage form, diagnosis, and how to use), and prescriber and dispenser information (full name, qualification, date of prescription/dispensing, signature or of prescriber) in the total included prescription was calculated. Prescribing indicator statistics also include the average number of drugs prescribed each issue (used as a degree of polypharmacy), the percentage of prescriptions written by generic name, antibiotic prescriptions, injectable prescriptions, and prescriptions from the national Essential Medicine List (EML). ${ }^{17}$ Thus,

1. The degree of polypharmacy $=\frac{\text { Total No of diffrent drug products prescribed }}{\text { Total No of prescriptions polled }}$

- Drug combinations prescribed for a single health issue were counted as one.

2. Drugs prescribed by generic name $(\%)=\frac{\text { No of drugs prescribed by generic name }}{\text { Total No of drugs prescribed }} \times 100$

3. Antibiotic prescriptions ( $\%)=\frac{\text { No of antibiotic prescribed }}{\text { Total No of prescriptions polled }} \times 100$

4. Injection prescriptions $(\%)=\frac{\text { No of injections prescribed }}{\text { Total No of prescriptions polled }} \times 100$

5. Drugs prescribed from EDL (\%) $=\frac{\text { No of prescribed from EDL }}{\text { Total No of drugs prescribed }} \times 100$

\section{Operational definitions}

\section{Private health sectors}

Are healthcare delivery firms owned by individuals or limited liability companies that are primarily limited to "for profit" purposes.

\section{Drug outlets}

Are dispensaries that have been legally registered as pharmacies or drug stores.

\section{Combination of drugs}

Two or more medications are prescribed to treat a specific health problem. Triple therapy for helicobacter pylori-induced peptic ulcer, for example, is regarded as one.

\section{Essential Medicines List}


Is a collection of essential drugs, or those that meet the population's most pressing healthcare needs. In this study, it was used interchangeably with other term "essential drug list."18

\section{Antibiotics}

When employed in the context of antibiotics, pharmaceuticals like penicillins, antibacterial, anti-infective drugs (such as dermatological and ophthalmological agents), as well as antidiarrheal drugs such as streptomycin, neomycin, and metronidazole, are also called antibiotics, in this study.

\section{Generic drug}

is a globally recognized International Nonproprietary Name (INN) that is public property. The 2014 Ethiopian EML was used to determine if drugs were generic or brand names. ${ }^{17}$

\section{Adherence to the basic prescription format}

Completing prescription format that prescribers adherence with some information such as patient, treatment and the compliance of professional information filling by prescriber and dispenser. ${ }^{19}$

\section{Results}

\section{WHO core prescribing indicators}

In the sampled prescriptions, a total of 2,192 medicines were prescribed. The average number of medications prescribed per encounter was found to be higher than $(1.83, \mathrm{SD}=0.9)$ the WHO standard norm after analyzing 1,200 prescriptions (Table 1). Out of all prescriptions, 973 ( $94.4 \%)$ contained two or fewer drugs per prescription, whereas $227(19.1 \%)$ contained three or more drugs per prescription, ranging from one to six medicines each encounter. Generic drugs made up around $1,431(65.3 \%)$ of all prescribed medications. At least one antibiotic was prescribed in nearly 766 (63.8\%) of all prescriptions. Only 929 (77.4\%) of prescriptions were prescribed by non-propriety names. Injections were prescribed in $137(11.5 \%)$ of the prescriptions examined. About 1,730 (78.9\%) of the medications were prescribed from Ethiopian EML.

Table 1

WHO prescribing indicator of prescription practice $(\mathrm{N}=1,200$ prescriptions)

\begin{tabular}{|llll|}
\hline Indicators & $\mathbf{N}(\% / \mathrm{SD})$ & Standard values & Value Source \\
\hline Average number of drugs per encounter & $1.83(0.9)$ & $1.6-1.8$ & \multirow{2}{*}{ WHO,(1995) } \\
\cline { 1 - 3 } Percentage of drugs in generic name & $1,431(65.3 \%)$ & $100 \%$ & \\
\cline { 1 - 3 } Percentage of Antibiotics & $766(63.8 \%)$ & $20-26.8 \%$ & \\
\cline { 1 - 3 } Percentage of injections & $137(11.5 \%)$ & $13-24.1 \%$ & \\
\cline { 1 - 3 } Percentage of drugs from national EML & $1,730(78.9 \%)$ & $100 \%$ & \\
\hline
\end{tabular}

Clinics are more likely $(P=0.026)$ than hospitals to prescribe more medication per patient (Table 2$)$. As a result, roughly $692(57.7 \%)$ of sample prescriptions had two or more medicines, and the prescriptions were obtained from clinics. The likelihood of prescribing generic medications did not significantly differ statistically by type of prescriber institution. The majority of injections were prescribed by hospitals, accounting for 28 ( $2.3 \%)$. Antibiotics were prescribed by hospitals in a higher number of prescriptions (40.3\%), and there was a statistical association in antibiotic prescriptions $(P=0.038)$. In clinic prescriptions, however, the poly antibiotic perscription per issue was observed (Fig. 1). Hospitals prescribed fewer antibiotic drugs ( $N=283 ; 23.6 \%)$ than clinics. Among all of the listed prescribing factors, drugstore outlets dispensed the most prescriptions.

Table 2

The prescription practice in prescriber and dispenser private facilities ( $N=1,200$ prescriptions)

\begin{tabular}{|c|c|c|c|c|c|c|c|c|c|c|}
\hline \multirow[t]{3}{*}{ Prescribing indicators } & \multicolumn{5}{|c|}{ Type of private health sector } & \multicolumn{5}{|c|}{ Type of private drug out let } \\
\hline & \multicolumn{2}{|l|}{ Hospital } & \multicolumn{3}{|l|}{ Clinic } & \multicolumn{2}{|c|}{ Pharmacy } & \multicolumn{3}{|c|}{ Drug store } \\
\hline & $\mathrm{N} / \mathrm{mean}$ & $\% / S D$ & $\mathrm{~N} /$ mean & $\% / S D$ & P-value & N/mean & $\% / S D$ & $\mathrm{~N} / \mathrm{mean}$ & $\% / S D$ & P-value \\
\hline Average number of drugs per encounter & 1.78 & 0.81 & 1.85 & 0.93 & 0.026 & 1.755 & 0.81 & 1.90 & 0.95 & 0.000 \\
\hline Percentage of drugs in generic name & 425 & $19.39 \%$ & 1,006 & $46 \%$ & 0.000 & 688 & $31.4 \%$ & 743 & $34 \%$ & 0.000 \\
\hline Percentage of injections & 28 & $2.3 \%$ & 109 & $9.1 \%$ & 0.000 & 19 & $1.6 \%$ & 118 & $10 \%$ & 0.000 \\
\hline Percentage of Antibiotics & 283 & $23.6 \%$ & 483 & $40.3 \%$ & 0.038 & 382 & $31.8 \%$ & 384 & $32 \%$ & 0.746 \\
\hline Percentage of drugs from national EML & 607 & $27.7 \%$ & 1,123 & $51 \%$ & 0.000 & 860 & $39.2 \%$ & 870 & $39.7 \%$ & 0.000 \\
\hline
\end{tabular}

\section{Completeness of the Prescription}


In this study, the completeness of the prescription was evaluated, including patient information, medication information, and professional information (Table 3). On more than 95 percent of the sample prescriptions, patient information such as age, sex, and full name of the patient was completed. The patients' weight, on the other hand, was the least likely to be filled on prescriptions. More over half of the prescriptions did not include information on the medication, such as the dosage form, diagnosis, or how to take it. Despite the fact that other treatment details on the prescription seemed to be more up to completed. Prescribers fill out the date of prescription 957 (79.8\%) and signature 1,127 (94\%) on the professional information form to a high degree.

Table 3

Completeness of prescriptions among prescriber and dispenser private facilities ( $N=1,200$ prescriptions)

\begin{tabular}{|c|c|c|c|c|c|c|c|}
\hline \multicolumn{2}{|c|}{ Patient information } & \multicolumn{2}{|c|}{ Treatment information } & \multicolumn{4}{|c|}{ Professional information } \\
\hline & & & & Prescribers & & Dispensers & \\
\hline Parameters & $N(\%)$ & Parameters & $N(\%)$ & Parameters & $N(\%)$ & Parameters & $N(\%)$ \\
\hline \multirow[t]{2}{*}{ Full name } & $1187(98.9)$ & Drug name & $1193(99.4)$ & Full name & $439(36.6)$ & Full name & $109(9.1)$ \\
\hline & & Drug strength & 1059 (88.3) & & & & \\
\hline Sex & $1156(96.3)$ & Dose & $1022(85.2)$ & Qualification & $309(25.8)$ & Qualification & $15(1.3)$ \\
\hline Age & $1143(95.3)$ & Frequency & $1170(97.5)$ & Date of prescription & $957(79.8)$ & Date of dispensing & $8(0.7)$ \\
\hline Weight & $28(2.3)$ & Duration & $1084(90.3)$ & Signature & $1127(94)$ & Signature & $322(26.8)$ \\
\hline \multirow[t]{3}{*}{ Card No. } & $651(54.3)$ & Dosage form & $426(35.5)$ & & & & \\
\hline & & Diagnosis & $380(31.7)$ & & & & \\
\hline & & How to use & 1048 (87.3) & & & & \\
\hline
\end{tabular}

Key indicators were checked simultaneously in each category to ensure adherence to all completeness indicators among the prescribed facilities (Table 4). As a result, prescribers from clinic health facilities are more likely to complete the patient information and treatment information indicators. The completeness of professional information was shown to be statistically significant $(P=0.000)$ across different types of institutions. Interestingly, no dispenser in the entire sample of prescriptions met all of the professional information requirements on single prescription paper.

Table 4

Completeness of prescriptions practice among different type of private healthcare facilities $(\mathrm{N}=1,200$

\begin{tabular}{|c|c|c|c|c|c|}
\hline \multirow[t]{3}{*}{ Completeness indicator } & \multicolumn{4}{|c|}{ The source of prescription (Type of Institution) } & \multirow[t]{3}{*}{ P-value } \\
\hline & \multicolumn{2}{|c|}{ Hospital } & \multicolumn{2}{|c|}{ Clinic } & \\
\hline & $\mathbf{N}$ & $\%$ & $\mathbf{N}$ & $\%$ & \\
\hline Patient information & 5 & $0.4 \%$ & 11 & $0.9 \%$ & 0.821 \\
\hline Treatment information & 27 & $2.3 \%$ & 73 & $6.1 \%$ & 0.127 \\
\hline Professional information of prescriber & 21 & $1.8 \%$ & 249 & $20.8 \%$ & 0.000 \\
\hline
\end{tabular}

\section{Discussion}

This study looked at 2,192 medicines that were prescribed on 1,200 prescriptions. As per the findings of this study, the average number of medications ordered per prescription from the private health sector in Addis Ababa was 1.83. This is slightly higher than the standard comparison (1.6-1.8). ${ }^{6}$ This result is consistent with two prior studies that conducted systematic reviews at the country level in Ethiopia and found that the pooled number of drugs per prescription exceeded WHO standards, accounting for 1.96 and 2.14, respectively, Ayenew et al ${ }^{20}$ and Bahiru et al. ${ }^{21}$ respectively. Poly-pharmacy was also recorded in the city as well as different parts of the country, according to study setting specialized studies. In Tikur Anbesa Specialized Hospital (TASH) in Addis Ababa, for example, the average number of medicines per prescription was found to be $1.89(\mathrm{SD}=1.16){ }^{22}$ According to the investigations, per prescription amounts of $(1.9)^{8},(2.34)^{23},(2.2)^{24},(2.13)^{25}$ were reported in Ethiopia's southern, eastern, northern, and south-west regions, respectively. The presence of polypharmacy in the country may indicate a constraint in prescribers having appropriate therapeutic training, variation in the health care delivery system, differences in socioeconomic profiles, as well as morbidity and mortality characteristics of the population, despite the fact that the factors have not yet been investigated. ${ }^{8}$ In this study, clinics are more likely to prescribe more medication per patient $(P=0.026)$ than hospitals.

The percentage of medications prescribed by generic name in the private health sectors evaluated was substantially below the standard average, at $65.3 \%$ (100\%). ${ }^{6}$ However, according to various Ethiopian studies, generic drugs make up more than $90 \%$ of Ethiopian prescriptions. In Ethiopian public facilities, for example, the percentage of pharmaceuticals administered by generic name was found to be $93.5 \%$ (89.13-97.96\%). ${ }^{21}$ Similarly, studies from public facilities in Addis Ababa $(88.5 \%)^{26}$ and among regions such as $90.61 \%$ in eastern Ethiopia ${ }^{23}, 98.7 \%$ in Hawassa ${ }^{8}, 97 \%$ in selected health facilities in eastern Ethiopia ${ }^{24}$, and $88 \%, 88.5 \%$, and $77.3 \%$ in North-west ${ }^{27}$, South-west ${ }^{19}$, respectively also showed higher percentages than the current study. Similarly, according to studies conducted in Ethiopia's southwest region, participants stated that brand prescribing has certainly grown. ${ }^{8,19}$ The higher score of public sectors could indicate

Page 5/10 
that the public health sector receives medication from the Ethiopian Pharmaceutical Supply Agency (EPSA), which purchases more generic pharmaceuticals. ${ }^{28}$ However, the lower rate of generic prescriptions from private health sectors in the current study could be due to a variety of factors. For example, there is no policy requiring private health care providers to purchase from public suppliers, which could lead to prescribers being influenced by factors such as the prescriber's personal characteristics, the cost of the medicine, and the marketing and promotion of importers and pharmaceutical companies. $^{29}$

The percentage of prescriptions containing antibiotics was $63.8 \%$ in this study, approximately three times the WHO limit (20-26.8\%). ${ }^{6}$ Similarly, Ethiopian public health institutions also show a high prevalence of antibiotic prescription, despite the fact that it is lower than the findings of this study. $8,20,21,25,30$ Antibiotics may be prescribed excessively for a variety of reasons. Various studies have found that Ethiopia has a high frequency of infectious illnesses ${ }^{31}$, as well as a lack of adherence to treatment protocols ${ }^{21}$ and a disparity in health professional understanding. ${ }^{32}$ Antimicrobial resistance is also on the rise, and there have been instances of hospitalization and mortality as a result of it. ${ }^{33}$ As a result, it is possible that Ethiopia's antimicrobial resistance danger is being exacerbated by over prescription of antibiotics. Antibiotic resistance has a considerable impact on medicine accessibility and healthcare financing in Ethiopia because of the high prevalence of poverty and limited resources. ${ }^{34}$

In the current study, the proportion of encounters in which injections were issued was $11.5 \%$, which is significantly lower than the WHO criterion (13-24.1\%). ${ }^{6}$ Ethiopian injection use is likewise below the standard, according to the combined results $18.3 \%, 13.2 \%$ of Ayenew et al ${ }^{20}$ and Bahiru et al. ${ }^{21}$ respectively. There has also been a global drop in injection usage. Professional and patient-related intervention efforts are amongst the most regularly mentioned factors. ${ }^{35}$ In Ethiopia, patients have a lower preference for injection dosage forms due to concerns about contamination and the belief that other dosage forms are equally effective. Injections, on the other hand, were preferred by health professionals for certain conditions including as pneumonia, tuberculosis, and urinary tract infections. ${ }^{36}$ In this study, there was a statistically significant correlation $(P=0.000)$ between private hospitals and clinics providing injections. This could indicate that the lower prevalence of injections in the private sector is linked to a commitment to their clients' demands. The lower incidence of therapeutic injection prescribing is recommended since it lowers the danger of infection via the parenteral route as well as the cost of treatment. ${ }^{37}$

In the present study majority of drugs 1,730 (78.9\%) in the private health, sectors were from national EDL however, lower than the WHO standard (100\%). ${ }^{6}$ however, The current study was lower similar studies done in public health sectors in Ethiopia..$^{8,20,21,25}$. The highly adherence to EDL of prescribing from both public and private could be due to the imported drugs are being well controlled by the Ethiopian Food and Drug Administration (EFDA) to assure their registration on the EDL. ${ }^{38}$ These could result in the better availably of essential drugs in the Ethiopian market so prescribers most likely prescribed those medicines. In the contrary, the lower adherence in private sectors might be critical since, compliance with the list of essential medicines is one of the key tools for a stable health care delivery system, as it ensures the availability and affordability of quality medicines at all care providers thereby promotes the rational use of medicines. ${ }^{39,40}$

In this study, patients' full names, ages, and sexes were mentioned in 99\%, 95.3\%, and $96.3 \%$ of prescription papers, respectively. The card number (54.3\%) and weight of the patient (2.3\%) were similarly poorly adhered to in this investigation. Similarly, age and sex were well-presented in study conducted in governmental facilities of South-Eastern Ethiopia, which revealed that age, sex, and card number were not mentioned in $18.2 \%, 23.7 \%$, and $60.2 \%$ of the encounters, respectively. ${ }^{25}$ This means that the majority of prescribers use the patient's name rather than a card number when prescribing a medicine, but TASH in Addis Ababa, Ethiopia, does the opposite. ${ }^{22}$ Therefore, the observed difference between private and government health facilities may be related to the burden flow of clients, which caused them to lean toward what was easiest to provide the service.

The treatment information, such as drug name, strength, dose, frequency, duration, and how to use, revealed that 85 to $99 \%$ of the prescriptions evaluated were adhered to. In this study, however, prescribers were less likely to complete out dosage forms (35.5\%) and diagnoses (31.7\%). Similarly, public healthcare facilities reported percentage variability that was lower than the standard (100\%) $8,16,41-43$ Medication errors, drug-related adverse events, and therapeutic failure may occur when medications are dispensed with insufficient labels ${ }^{6}$. As a result, practitioners are required to be enforced to label each and every drug given to patients.

In terms of this prescriber's information, only $36.6 \%$ and $25.8 \%$ of prescribers wrote their name and qualification, respectively. While a higher percentage of prescriptions $79.8 \%, 94 \%$ were filled with their day of prescriptions and signatures, respectively, to ensure they took responsibility for any responsibilities. Only $27(2.3 \%)$ and $73(6.1 \%)$ of prescribers $(P=0.127)$ met all of the characteristics in their information from the hospital and clinic, respectively. Prescriptions in the public sector, on the other hand, scored differently than those in the private sector. According to Admassie et al, 33.4\%, $96.7 \%, 72.6 \%$ and $16.1 \%$ of prescriptions have the prescriber's name, signature, date, and qualification. ${ }^{44}$ Furthermore, in another investigation, the name of the prescriber was found in $82 \%$ of the prescriptions examined. ${ }^{45}$ The disparity across both sectors could imply a difference in perceptions of the value of prescribing information. Furthermore, because of this poor practice, identifying the accountable prescriber for any feedback or explanation is challenging. Moreover, this study revealed, obtaining prescription papers with the full name, qualification, date of dispensing, and signature of the dispenser is extremely difficult; only $9.1 \%$, $1.3 \%, 0.7 \%$, and $26.8 \%$ of dispensed prescriptions contained such information, respectively. Interestingly, no dispenser filled out all of this information in a single prescription. However, in the pediatric emergency unit of a tertiary hospital in Lagos, Nigeria, for example, the dispensers placed their signature following a refill in $92.1 \%$ of prescriptions. ${ }^{42}$ Because the type and contents of the prescriptions used by the practitioner differed, the preparation and execution of standard prescriptions in all departments and units of the hospital was critical. Due to the relevance of rational drug use and private sector practice in Ethiopia; health practitioners must be given with regulatory interventions and strategies, close monitoring from concerned bodies, and regular training on proper prescribing and dispensing practice to encourage rational drug use is required in our context.

\section{Limitation of the study}


There are some drawbacks to this study. These limitations, however, do not invalidate the study's findings because all of the WHO-recommended procedures were used. Despite the fact that this study attempted to cover all of the WHO core drug use and prescription indicators, the smaller sample size of completeness and prescription pattern indicators, as well as the study's limited scope, may limit the generalizability of these specific components to the general population. Because to financial constraints and the current pandemic (COVID-19), we have chosen to limit it to only eight drug outlets. Multiinstitutionally and sampling approaches could help to overcome the limitation in generatability. This study, on the other hand, provided useful information on the private sector's practice of prescribing and dispensing patterns.

\section{Conclusion}

In this study, the WHO core drug use indicators and prescription completeness were used to assess the practice of private health sectors in Addis Ababa in terms of drug use patterns and prescription completeness. It was shown that the average number of drugs prescribed per encounter was higher than the WHO limit. The proportion of drugs administered by generic name was significantly lower than the standard average. The proportion of antibiotic-containing prescriptions was around three times the WHO limit. Injections were prescribed in a lower percentage of encounters than the WHO requirement. However, the majority of the medications were from the national EDL, which was lower than the WHO guideline. Only a few prescribers filled out all of the required information, such as patient information, treatment information, and the prescriber's professional information. Interestingly, no dispenser has ever been discovered to complete all of the needed information on a single prescription's dispenser information blanket.

In this investigation, poor rational prescription patterns and adherence to basic prescription information were observed. Because of the importance of rational drug use and private sector practice in Ethiopia, health practitioners must be provided with regulatory interventions, continuous monitoring from concerned bodies and regular training on proper prescribing and dispensing practice to promote rational drug use.

\section{Abbreviations}

EML/EDL: Essential Medicines/Drugs List of Ethiopia, EFDA: Ethiopian Food and Drug Administration, EPSA: Ethiopian Pharmaceutical Supply Agency, FMOH: Federal Ministry of Health of Ethiopia, INN: International Nonproprietary Name, SD: Standard Deviation, SPSS: Statistical Package for the Social Sciences, TASH: Tikur Anbesa Specialized Hospital, WHO: World Health Organization

\section{Declarations}

\section{Ethics approval and consent to participate}

The ethical clearance and study approval was obtained from Alkan health science business and technology college, research and ethics committee (official letter no AHTSBTC/002/519/13). Because this was a retrospective study, the college's research and ethics committee did not seek patient consent for the review of their medical information. To maintain the privacy of study participants and the confidentiality of their personal information, names of study participants were excluded from the data collection format.

\section{Availability of data and materials}

On additional file 1 and 2, one may find the data that supports the result of this article.

\section{Additional files}

Additional file 1: Prescribing core indicators data. (SAV 29.7 KB)

Additional file 2: Prescription adherence indicators data. (SAV 62.9 KB)

\section{Authors' contributions}

DT, NE, WA and GA were in responsible of data collecting, data entry. GA and NE analyzed, as well as wrote the draft manuscript. GA designed the project, contributed to its design, modified data collection instruments, and revised the manuscript. The final manuscript was read and approved by all of the authors.

\section{Acknowledgment}

We are grateful to the pharmacies for providing the requested information within days of our request. Finally, we would want to express our gratitude to Alkan Health Science Business \& Technology College for providing us with the chance to conduct this study.

\section{Conflict of interest}

There will be no conflicts of interest for any of the authors. 


\section{Funding}

None

\section{Consent for publication}

Not Applicable

\section{References}

1. Mehreen A. Irrational Prescribing Practices: A Threat To Underdeveloped World. Int J Pharma Sci Sci Res. 2017,3(1):21-25. doi:10.25141/2471-6782-20171.0021

2. EFDA. Good Prescribing Manual for Ethiopia. Drug Administration. http://www.fmhaca.gov.et/publication/good-prescribing-manual-for-ethiopia-new-2/. Published 2011.

3. T B, Zafar MZ, Ahsan M, Asim M, Huzaifa MA. Study of Rational and Irrational Prescribing in Different Government and Private Health Care Centres of Punjab. J Pharmacovigil. 2018,06(01). doi:10.4172/2329-6887.1000250

4. Aravamuthan A, Arputhavanan M, Subramaniam K. Assessment of current prescribing practices using World Health Organization core drug use and complementary indicators in selected rural community pharmacies in. J Pharm Policy Pract. 2017:1-6. doi:10.1186/s40545-016-0074-6

5. WHO. World Health Organization Promoting Rational Use of Medicines: Core Components. Geneva:, 2002.

6. Ghei P. How to Investigate Drug Use in Health Facilities. Selected Drug Use Indicators. Vol 34. Geneva, Switzerland., 1995. doi:10.1016/01688510(95)90068-3

7. Okeke IN, Lamikanra A, Edelman R. Socioeconomic and behavioral factors leading to acquired bacterial resistance to antibiotics in developing countries. Emerg Infect Dis. 2017,5(1):18-27. doi:10.3201/eid0501.990103

8. Desalegn AA. Assessment of drug use pattern using WHO prescribing indicators at Hawassa University teaching and referral hospital , south Ethiopia: a cross-sectional study. 2013.

9. Debalto D, Gobe Z TS. A base line survey of prescribing indicators and factors influencing prescribing in southern Ethipia. $J$ Heal Dev. 1991:11:263-7.

10. FMHACA. Manual for Medicines Good Prescribing Practice. Addis Ababa, Ethiopia, 2012. www.masterprintingpressplc.com.

11. H. Tadeg, E. Ejigu, E. Geremew AA. Findings of the Baseline Assessment at Federal, Addis Ababa, and Teaching Hospitals. Audit Pharm Trans Serv. 2014. http://apps.who.int/medicinedocs/documents/\%0As21704en/s21704en.pdf.

12. Zeleke K, Fenta TG. Extended Roles of Community Pharmacists in Addis Ababa: Extent of Use and Publics' Perceptions. Ethiop Pharm J. $2017,32(2): 147$. doi:10.4314/epj.v32i2.5

13. Nair VD, Morankar S, Jira C, Tushune K. Private hospital sector development: an exploratory study on providers perspective in addis ababa, ethiopia. Ethiop J Health Sci. 2011,21(Suppl 1):59-64. http://www.ncbi.nlm.nih.gov/pubmed/22435009\%0Ahttp://www.pubmedcentral.nih.gov/articlerender.fcgi? artid=PMC3275879.

14. News B. Lemi kura sub city administration. https://www.google.com/url? $s a=t \& r c t=j \& q=\& e s r c=s \&$ source=web\&cd=\&cad=rja\&uact=8\&ved=2ahUKEwjzqr3NqLryAhXyyYUKHRF4DqIQFnoECAUQAQ\&url=https\%3A\%2F\%2Fborkena.cc ababa-city-administration-restructuring-new-sub-city\%2F\&usg=AOvVaw2YUv8XZN. Published 2020.

15. Huang K-C. Mixed random systematic sampling designs. Metrika. 2004,59(1):1-11. doi:10.1007/s001840300264

16. Ghei P. How to Investigate Drug Use in Health Facilities. Selected Drug Use Indicators. Vol 34. Geneva, 1995. doi:10.1016/0168-8510(95)90068-3

17. FMHACA. National Medicine List. Fifth. Addis Ababa, Ethiopia, 2015. https://www.who.int/selection_medicines/country_lists/EML_5th_edition_2015.pdf.

18. World Health Organization. Promoting Rational Use of Medicines: Core Components. Geneva, Switzerland., 2002.

19. Angamo MT, Wabe NT, Raju NJ. Assessment of patterns of drug use by using world health organization's prescribing, patient care and health facility indicators in selected health facilities in southwest ethiopia. J Appl Pharm Sci. 2011,1(7):62-66.

20. Wondim A, Getahun A, Atsede G. Prescribing pattern of medications prescribed to outpatients based on WHO prescribing indicators in Ethiopia: A systematic review and meta-analysis of observational studies. African J Pharm Pharmacol. 2020,14(7):240-249. doi:10.5897/AJPP2020.5123

21. Tefera BB, Getachew M, Kebede B. Evaluation of drug prescription pattern using World Health Organization prescribing indicators in public health facilities found in Ethiopia: systematic reviews and meta-analysis. J Pharm Policy Pract. 2021,14(1):31. doi:10.1186/s40545-021-00313-y

22. Assefa, Tamra, Birhanu Abera, Tiya Bacha and GB. Prescription Completeness and Drug Use Pattern in the University Teaching Hospital, Addis Ababa, Ethiopia. J Basic Clin Pharma. 2018,(November):90-95.

23. Sisay M, Mengistu G, Molla B, Amare F, Gabriel T. Evaluation of rational drug use based on World Health Organization core drug use indicators in selected public hospitals of eastern Ethiopia: A cross sectional study. BMC Health Serv Res. 2017,17(1):1-9. doi:10.1186/s12913-017-2097-3

24. Bilal Al, Osman ED, Mulugeta A. Assessment of medicines use pattern using World Health Organization 's Prescribing , Patient Care and Health facility indicators in selected health facilities in eastern Ethiopia. BMC Health Serv Res. 2016,(December). doi:10.1186/s12913-016-1414-6

25. Abdella SH, Wabe NT. Prescribers adherence to the basic principles of prescription orders writing in South West Ethiopia. Natl J Physiol Pharm Pharmacol. 2012,2(1):66-70. 
26. Berha AB, Seyoum N. Evaluation of Drug Prescription Pattern Using World Health Organization Prescribing Indicators in Tikur Anbessa Specialized Hospital: a Cross-Sectional Study. J Drug Deliv Ther. 2018,8(1). doi:10.22270/jddt.v8i1.1652

27. Demeke B, Molla F, Assen A, et al. Evaluation of Drugs Utilization Pattern Using Who Prescribing Indicators in Ayder Referral Hospital , Northern. Int $J$ Pharma Sci Res. 2015,6(2):343-347.

28. PFSA. Pharmaceuticals procurement list. www.pfsa.gov.et Accessed date December 12,2018. Published 2018.

29. Davari M, Khorasani E, Tigabu BM. Factors Influencing Prescribing Decisions of Physicians: A Review. Ethiop J Health Sci. 1970,28(6). doi:10.4314/ejhs.v28i6.15

30. Wubetu M, Derebe D, Mulaw T, Yimer T, Hailu G. Assessment of Drug Prescription Pattern in Two District Hospitals, Northwest Ethiopia. J Heal Educ Res Dev. 2018,06(01). doi:10.4172/2380-5439.1000246

31. Misganaw A, Haregu TN, Deribe K, Tessema GA, Deribew A, Melaku YA et al. National mortality burden due to communicable, non-communicable, and other diseases in Ethiopia, 1990-2015. Popul Health Metr. 2017,15(1):2019-23.

32. FMOH. Health and health related indicator of Ethiopia. (2016/2017). 2017:42.

33. Pramanik MA MM. Impact of Overuse of Antibiotics on human health. ResearchGate. 2017,6(3):1-9. Retrieved from https://www.researchgate.net/p.

34. United States Agency for International Development. Health Care Financing Reform in Ethiopia: Improving Quality and Equity. http://www.healthsystems2020.org/\%0Acontent/resource/detail/85865/function.mysql-connect. Published 2012.

35. Roy É, Arruda N, Bruneau J, Jutras-Aswad D. Epidemiology of Injection Drug Use. Can J Psychiatry. 2016,61(3):136-144. doi:10.1177/0706743716632503

36. Zewdie A, Wabe N. The prevalence of therapeutic injections in Ethiopia: from the patients and \#8217, and health care providers and \#8217, perspectives. Gaziantep Med J. 2012,18(1):21. doi:10.5455/GMJ-30-2011-62

37. Ghimire S, Nepal S, Bhandari S, Nepal P, Palaian S. A prospective surveillance of drug prescribing and dispensing in a teaching hospital in Western Nepal. J Pak Med Assoc. 2009,59(10):726-731.

38. World Bank Group, Global Financing Facility, Ministry of Health-Ethiopia. ETHIOPIA HEALTH PRIVATE SECTOR ASSESSMENT October 2019. 2019, (October).

39. IMS. Understanding the Role and Use of Essential Medicines Lists. IMS Institute for Healthcare Informatics, USA. 2015,(April):14-17.

40. Atif M, Malik I, Dawoud D, Gilani A, Ahmed N, Babar ZUD. Essential medicine list, policies, and the world health organization. Encycl Pharm Pract Clin Pharm. 2019:239-249. doi:10.1016/B978-0-128-12735-3.00061-3

41. Jain S. Assessment of prescription pattern in a private teaching hospital in India. Int. Pharma Sci,1. 2013,3:219-22.

42. Aina BA, Egbehor UC. Study of completeness of prescriptions in paediatrics emergency section of a tertiary hospital in Lagos, Nigeria. J Appl Pharm Sci. 2013,3(5):75-79. doi:10.7324/JAPS.2013.3514

43. Miljeteig I, Defaye FB, Wakim P, et al. Financial risk protection at the bedside: How Ethiopian physicians try to minimize out-of-pocket health expenditures. PLoS One. 2019,14(2):1-16. doi:10.1371/journal.pone.0212129

44. Admassie E BB and HW. Assessment of Drug Use Practices and Completeness of Prescriptions in Gondar University Teaching Referral Hospital. Int $J$ Pharm Sci Res. 2013,4(1):265-275.

45. Babar HS, Hussain S, Maqsood Z, et al. Adherence to prescription format and compliance with who core prescribing indicators. J Pharm Sci Res. 2014,6(4):195-199.

\section{Supplementary}

Supplementary files not available with this version

\section{Figures}




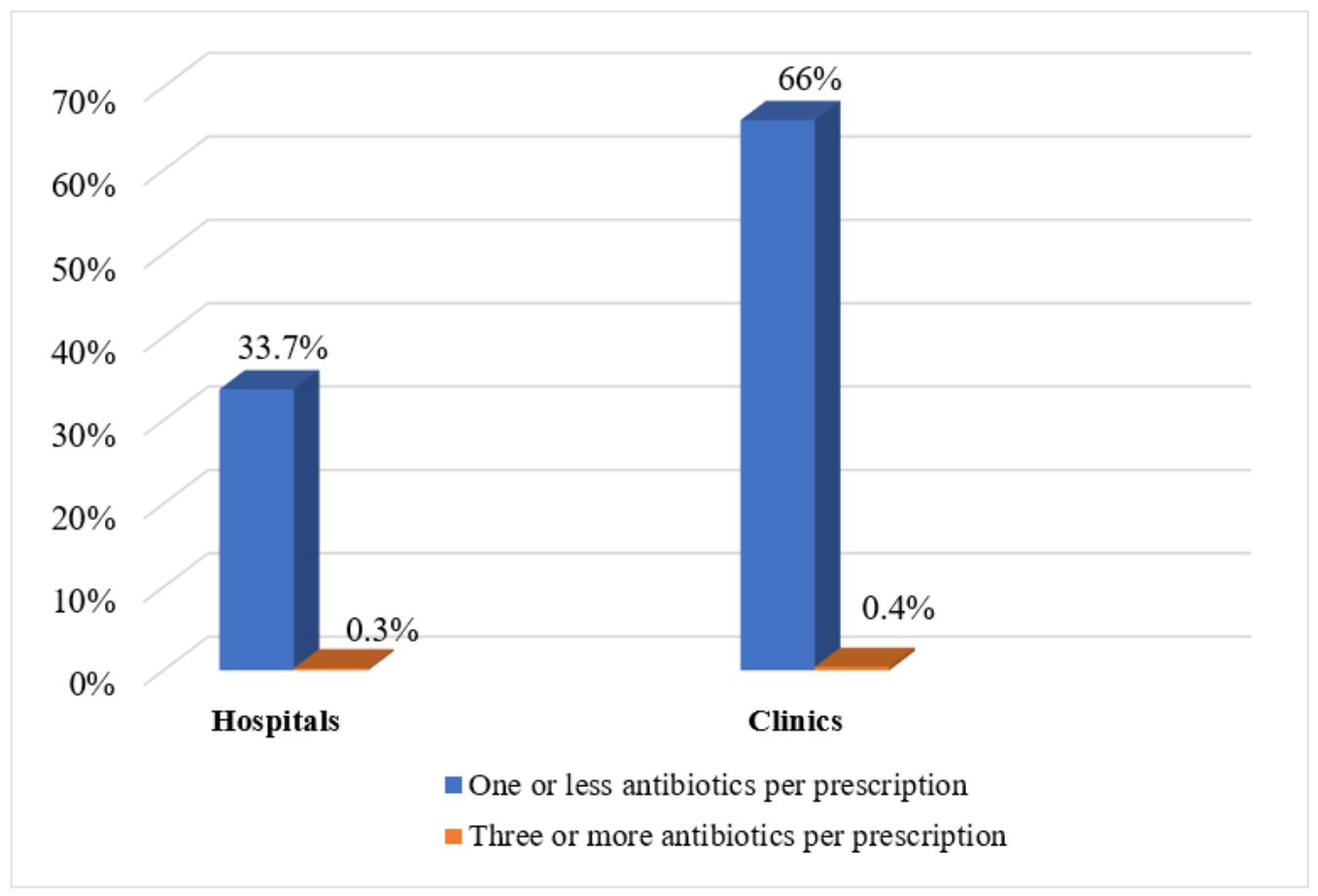

Figure 1

The percentage of number of prescribing antibiotics per prescription ( $\mathrm{N}=500$ prescriptions) 